REYISTA

dete

CEPA

NUMERO 62

AGOSTO 1997

SANTIAGO DE CHILE

OSCAR ALTIMIR

Direcsor

EUGENIO LAHERA

Secretario Técnico

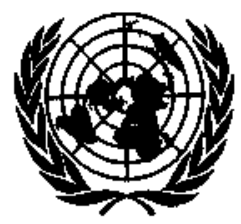

NACIONES UNIDAS 
Estado, comunidad y sociedad en el desarrollo social

Fermando Henrique Cardoso

Un balance de las reformas estructurales neoliberales en América Latina

Joseph Ramos

Deuda y sostenibilidad ffscal: ise repite la historia?

Guillermo E. Perry

Reformas petroleras: las opciones en juego

Fernando Sánchez Albavera

Las organizaciones indígenas: actores emergentes en

América Latina

Rodolfo Stavenhagen

El empleo rural no agropecuario en el Istmo Centroamericano

Jürgen Weller

Marginalidad e integración social en Uruguay

Rubén Kaztman

La política comercial en el marco de la Organización Mundial

de Comercio

Diana Tussie

Comercio y medio ambiente: ¿luz verde o luz roja?

Helga Hoffmann

Anclas nominales y escenarios de coordinación macroeconómica en el MERCoSUR

Gonzalo Rodríguez Prada

Políticas de promoción de exportaciones en Centroamérica

Larry Willmore

Publicaciones recientes de la CEPAL 


\section{Políticas de promoción de exportaciones en Centroamérica}

\section{Larry Willmore}

Oficial de Asuntos Económicos. División de Análisis

Microeconomico y Social, Naciones Unidas, Nueva York
Diez años atrás, los países miembros del Mercado Común Centroamericano (Costa Rica, El Salvador, Guatemala, Honduras y Nicaragua) comenzaron a abandonar la política de "desarrollo hacia adentro" que habían aplicado durante decenios. Actualmente están estimulando las exportaciones no tradicionales mediante la reducción de tas barreras arancelarias, la uniticación del tipo de cambio y el acceso de los exportadores a los bienes intermedios y de capital a precios internacionales. Algunos gobiernos, además, han otorgado subsidios directos en la forma de créditos tributarios por los bienes que se exportan fuera de Centroamérica. El presente artículo pasa revista a esas políticas y analiza sus efectos en las exportaciones de cada uno de los cinco países centroamericanos, y examina en especial la posibilidad de que tos subsidios que se otorgan por los productos que se despachan fuera del MCCA puedan inducir a los exportadores a dar preferencia a los mercados extrarregionales en vez de los regionales. 


\section{I}

\section{Introducción}

Las economías centroamericanas son pequeñas en todo el sentido de la palabra. Sus exportaciones y sus importaciones no influyen en los precios internacionales, de modo que para todas ellas la política óptima es el libre comercio.' Aun así, los cinco miembros del Mercado Común Centroamericano (MCCA), tanto individual como colectivamente, han aplicado políticas comerciales proteccionistas, en la mayoría de los casos gravando las importaciones con aranceles elevados. La protección arancelaria actúa como un verdadero impuesto inadvertido sobre las exportaciones, cuyo efecto se ha tratado de contrarrestar mediante la baja de aranceles y la aplicación de políticas que incluyen: el comercio preferencial, por medio del cual los países subsidian recíprocamente sus exportaciones; las zonas de maquila; los regímenes de admísión temporal; los subsidios directos a las exportaciones, y los controles cambiarios, que por lo general desalientan la exportación pero que en Centroamérica suelen utilizarse para subvencionar las exportaciones no tradicionales. Este astículo analiza brevemente cada una de tales políticas y sus efectos en las exportaciones no tradicionales. Cabe seña-

\section{II}

\section{Las políticas}

\section{t. La protección como impuesto a las exportacio- nes}

No es raro que los gobiernos de los países que se especializan en producir y exportar un número reducido de productos quieran diversificar sus economías otor-

\footnotetext{
I..] Una versión anterior de este trabajo fue presentada en el Primer Foro de Promoción de las Exportaciones, realizado en Nicaragua el 12 de junio de 1996. El autor desea agradecer las útiles observaciones y sugerencias de Alexander Hoffmaister, Jean-Claude Milleron y del comentarista anónimo al que se le encomendó la lectura de este trabajo.

'El café y los bananos son quizá una excepción, pero Centroamética no puede hacer subir los precios ni síquiera en et caso de estos productos, salvo que cuente con el apoyo de los productores de otras regiones del mundo.
}

lar que todas estas políticas son subóptimas (second best) y no serían necesarias si los países liberalizaran totalmente el comercio mediante la eliminación unilateral de toda la protección arancelaria y de las cuotas.

Hay que hacer hincapié en que el libre comercio no es sinónimo de laissez-faire. En efecto, adherir al libre comercio no impide que los gobiernos graven o subvencionen la producción o el consumo de determinados bienes. Sin embargo, en un sistema de libre comercio los impuestos y subsidios que afectan la producción de un bien determinado son iguales para el producto que se exporta y el que se vende en el mercado interno, y los que afectan el consumo son iguales ya sea que el producto se importe o que lo proporcione un productor local. Si los impuestos sobre artículos suntuarios como cosméticos, televisores y automóviles gravan únicamente a los importados, se estimula su producción local a un costo elevado para evitar el pago del impuesto; aunque se les disfrace como impuestos al consumo, la verdad es que constituyen gravámenes arancelarios sobre las importaciones.

gando incentivos a la producción de un mayor número de bienes. La idea es que los incentivos sean transitorios, y que las 'industrias incipientes' se desarrollen y con el tiempo prosperen sin necesidad de privilegios especiales.

Por lo general, los economistas aconsejan a los gobiernos que subsidien abiertamente las actividades nuevas en vez de recurrir a la protección arancelaria. ${ }^{2}$ Los recursos necesarios se pueden obtener mediante impuestos generales al consumo o a los ingresos, o mediante gravámenes sobre bienes cuyo consumo o pro-

\footnotetext{
2 Véase, por ejemplo, en Caves y Jones (1973, pp. 254-260) la tesis de que para lograr una determinada diversificación de la producción es siempre mejor establecer un impuesto óptimo unido a un subsidio, en vez de un gravamen sobre las importaciones.
} 
ducción deba desalentarse. Pero las autoridades eco* nómicas rara vez acogen este consejo y los gobiernos usualmente promueven las industrias valiéndose de la protección arancelaria y restringiendo las importaciones, en vez de otorgar subsidios en efectivo. A la postre, los consumidores subvencionan a los productores protegidos cuando pagan por los productos nacionales un precio más alto del que pagarían si importaran bienes de calidad similar libres de impuestos.

La protección arancelaria tal vez estimule el desarrollo de industrias nuevas, pero tiene el inconveniente de que actúa como un impuesto sobre las exportaciones, tanto tradicionales como no tradicionales. ${ }^{3} \mathrm{De}$ hecho, los aranceles y otras restricciones a las importaciones se traducen en dos tipos diferentes de impuestos a las exportaciones. Primero, cuando se protege la producción de bienes intermedios, aumentan los costos de las industrias que los utilizan como insumos; por ejemplo, si se obliga a los modistos a pagar impuestos por las telas importadas o a adquirir telas caras y de mala calidad a las industrias textiles tocales, por eficientes que sean les será muy difícil competir en los mercados de exportación. Segundo, y de manera más sutil, la protección arancelaria provoca una sobrevaloración del tipo de cambio y disminuye el poder de compra de la moneda local que los exportadores reciben por cada divisa que ganan.

A manera de ejemplo de esta segunda forma en que la protección puede actuar indirectamente como un impuesto a las exportaciones, supóngase que un país con tipo de cambio flexible elimine el arancel uniforme de $20 \%$ que grava las importaciones. Cabe preguntarse qué sucederá con el valor de las divisas. Indudablemente, como ahora las importaciones resultarán más baratas en moneda local, aumentará la demanda de divisas y habrá una consiguiente alza de su precio. En otras palabras, en términos reales la moneda local se depreciará y los exportadores recibirán más pesos por cada dólar de ingresos. La diferencia entre este tipo de cambio con libre comercio y el con protección arancelaria equivale a un impuesto a las exportaciones. Se trata de un impuesto difícil de describir y más aún de medir, pero que de hecho existe y efectivamente inhibe las exportaciones no tradicionales.

En los años sesenta, Centroamérica fortaleció sus políticas proteccionistas adoptando un arancel externo

\footnotetext{
${ }^{3}$ La tesis de que los impuestos a las importaciones equivalen a gravar las exportaciones, demostrada por Lerner ([936) respecto del modelo de dos productos, fue ampliada a un mayor número de productos por Corden (1971, pp. 119-122).
}

común muy superior a cualquiera de los cinco aranceles nacionales que reemplazo. ${ }^{4}$ Como lo expresó la Secretaría Permanente del Tratado General de Integración Económica Centroamericana (SIECA), "Centroamérica, al constituir el Mercado Común, enunció desde el principio una política de industrialización y desarro1 lo 'hacia adentro' y, como parte de ésta, se concibieron distintos instrumentos, de los cuales el más importante fue un arancel de clara orientación proteccionista..." (SIECA, 1974, p. 38).

Durante un tiempo, esta política consistente en fomentar las actividades nuevas medjante una alta protección arancelaria produjo una diversificación de las economías centroamericanas y se acompañó de un significativo crecimiento económico. En 1960-1977 los cinco países de la región registraron tasas de crecimiento anual medio superiores al 5\%. Sin embargo, a contar de fïnes de los años setenta, el crecimiento disminuyó notoriamente en todos ellos. En El Salvador y Nicaragua tal vez era inevitable que la tasa de crecimiento fuera negativa, debido a la guerra civil, pero las otras tres economías también exhibieron falta de dinamismo (cuadro l).

Una serie de sucesos externos, a saber, la segunda crisis originada por alzas de los precios del petróleo que se produjo en 1979-1980, el aumento de las tasas de interés y la caída de los precios de las exportaciones tradicionales, redujo enormemente la disponibilidad de divisas y tuvo efectos negativos en el ingreso real de la región. ${ }^{5}$ La reacción de las economías a este medio externo adverso dejó mucho que desear, por lo que algunos centroamericanos llegaron a la conclusión de que había que abandonar la antigua estrategia de 'desarrollo hacia adentro'. El primero en promover la idea de simplificar y reducir la estructura de protección fue Costa Rica, que en 1985 logró persuadir a los demás miembros del MCCA de que había que modificar radicalmente los aranceles externos. Al año siguiente tres gobiernos realizaron la reforma, pese a que ello significó abandonar transitoriamente el principio del arancel externo común. En 1987, Costa Rica anunció su meta de llegar unilateralmente a un arancel máximo de $40 \%$ a fines de 1990 . En 1989, el nue-

\footnotetext{
${ }^{4}$ El promedio no ponderado del arancel que gravaba los bienes de consumo no duraderos se elevo de $68 \%$ a $122 \%$. Véanse mayores detalles $y$ análisis en Wilmore (1976).

${ }^{5}$ Estas conmociones externas también seîalarón el fín de la estabilidad de precios en la región. Véase un análisis del tema en Escaith y Schatan (1996)
} 
Centroamérica: Crecimiento anual del producto interno bruto, 1960-1996

(Porcentajes)

\begin{tabular}{lrrrrrrrrr}
\hline & $\begin{array}{c}1960- \\
1977\end{array}$ & $\begin{array}{c}1977- \\
1989\end{array}$ & 1990 & 1991 & 1992 & 1993 & 1994 & 1995 & 1996 \\
\hline Costa Rica & 6.6 & 2.7 & 3.6 & 2.3 & 7.7 & 6.3 & 4.5 & 2.5 \\
El Salvador & 5.4 & -0.1 & 3.4 & 3.6 & 7.5 & 7.4 & 6.0 & 6.1 & 3.0 \\
Guatemala & 5.7 & 2.3 & 3.1 & 3.6 & 4.8 & 3.9 & 4.4 & 4.9 & 3.0 \\
Honduras & 5.5 & 3.4 & 0.1 & 3.3 & 5.6 & 6.1 & -1.4 & 3.6 & 3.5 \\
Nicaragua & 5.9 & -2.8 & -0.1 & -0.2 & 0.4 & -0.4 & 3.3 & 4.5 & 5.5 \\
\hline
\end{tabular}

Fuente: Naciones Unidas, Departamento de Informacion Económica y Social y Análisis de Políticas (DESIPA), sobre la base de las cuentas nacionales.

vo gobierno de El Salvador le ganó la delantera a Costa Rica en materia arancelaria cuando en septiembre redujo el arancel máximo a 50\%, y luego a 35\% en marzo siguiente.

El 17 de julio de 1991, en la Declaración de El Salvador, los cinco presidentes de Centroamérica se comprometieron a volver antes de 1995 a un arancel externo común, pero menos proteccionista, de un $20 \%$ como máximo y un $5 \%$ como mínimo. Como se desprende de los datos que figuran en el cuadro 2, este objetivo no pudo lograrse. A comienzos de 1995, sólo Costa Rica se había situado en el rango previsto. La situación cambió en marzo de ese año cuando, por razones fiscales, este país estableció una sobretasa de $8 \%$ sobre todas las importaciones y aumentó los derechos de importación a un rango de 13 a $28 \%$. En abril de 1995, El Salvador, seguido de Guatemala en diciembre, redujo a un $1 \%$ los derechos aduaneros que gravaban los bienes de capital, con lo cual se acentuó aún más la disparidad de los aranceles externos. Durante todo este período, Nicaragua mantuvo esos derechos en un nivel bastante más alto que el aplicado en los otros cuatro países. Sin embargo, actualmente todos los

CUADRO 2

Centroamérica: Derechos aduaneros y sobretasas a las importaciones, ad valorem, comienzos de 1992 y 1995

(Porcentajes)

\begin{tabular}{lcc}
\hline & 1992 & 1995 \\
\hline Costa Rica & $5-46$ & $5-20$ \\
El Salvaldor & $5-30$ & $5-30$ \\
Guatemala & $5-30$ & $6-21$ \\
Honduras & $5-35$ & $7-22$ \\
Nicuragua & $5-60$ & $10-40$ \\
\hline
\end{tabular}

Fuente: Willmore, 1992, cuadro L; The Economist Intelligence Unit, Country Reports. países de la región aplican barreras arancelarias inferiores a las de los años sesenta, setenta y ochenta, por lo que el impuesto implícito sobre las exportaciones también es más bajo. Todos han liberalizado el comercio más de lo exigido para incorporarse al Acuerdo General sobre Aranceles Aduaneros y Comercio (GATT), hoy Organización Mundial de Comercio (OMC).

Las cuotas de importación, que provocan el alza de los precios internos de los productos involucrados, también actúan como un impuesto sobre las exportaciones. Los gobiernos centroamericanos casi siempre han optado por proteger a los productores de sus países mediante aranceles, en vez de imponer restricciones cuantitativas. Sin embargo, todos ellos han recurrido de vez en cuando al sistema de licencias de importación, más que nada por necesidad de racionar las divisas que se venden a un precio oficial artificialmente bajo. En los últimos años han evitado tanto los tipos de cambio artificiales como las licencias de importación.

\section{Los acuerdos comerciales preferenciales como subsidio a las exportaciones}

Cuando se gravan las importaciones, los productores pueden subir los precios y disminuir la calidad de los productos que venden en el mercado local, de modo que los aranceles pueden considerarse un impuesto al consumo otorgado al productor en forma de subsidio. Lo mismo cabe decir de acuerdos comerciales preferenciales tales como el MCCA, con la diferencia de que en este caso consumidor y productor no necesitan estar domiciliados en el mismo país: es posible que personas que residen en un país subsidien las exportaciones de otro. Dicho de otra manera, los productores del MCCA que exportan a un país asociado están exentos del pago del arancel externo, de modo que son subsidiados 
por los consumidores de ese país, que les pagan precios más altos que los internacionales. ${ }^{6}$

Esta forma de subsidio no se limita a las exportaciones al MCCA, sino que es inherente a cualquier tipo de acuerdo de comercio preferencial. Los tratados bilaterales que Costa Rica y otros parses centroamericanos han suscrito con Panamá permiten que los consumidores centroamericanos subsidien las exportaciones panameñas a cambio de que Panamá subsidie las exportaciones centroamericanas. El hecho de que la firma costarricense Gallito exporte a Panamá un volumen apreciable de confites obedece a su acceso preterencial al mercado protegido de Panamá y no a que este productor costarricense sea competitivo en los mercados mundiales. Del mismo modo, el éxito de los maquiladores centroamericanos y del Caribe se debe en gran medida a que el mercado de vestuario de los Estados Unidos está protegido mediante cuotas por países.

\section{Las zonas de maquila}

Uno de los dos tipos de 'impuestos' con que la protección grava las exportaciones tradicionales es el mayor costo de los insumos intermedios. Los exportadores pueden evitarlo instalandose fuera del territorio aduanero de un país, en lugares conocidos como zonas francas o zonas de maquila. La propiedad y administración de estas zonas pueden ser privadas o públicas. En cualquiera de los dos casos, los exportadores alquilan una estructura física básica que proporciona la administración de la zona, y están exentos de impuestos sobre sus utilidades, sus importaciones y sus exportaciones. Y lo que es más importante, también evitan muchos de los costos burocráticos que lleva envuelto tratar con las autoridades aduaneras. A cambio de estos privilegios, los productores de las zonas francas se obligan a exportar la totalidad de su producción. En algunas oportunidades se les autoriza para 'exportar' al territorio aduanero, pero se parte de la base de que los bienes que se producen en una zona franca son foráneos, por lo que deben pagar todos los derechos aduaneros y los impuestos al consumo correspondientes.

Cabe señalar que en las zonas francas no hay un sesgo antiexportador. En todo caso, el sesgo sería favorable a las exportaciones puesto que los gobiernos restringen las ventas al mercado local mientras que no

\footnotetext{
${ }^{5}$ El razonamiento parte de la base de que los países pagan por los bienes que importan. Si se acumulan déficit sin pagar, como ha solido suceder en el MCCA, no queda en claro quién subsidia a quién.
}

imponen limitación alguna a los embarques destinados a los mercados externos. Con todo, las empresas que operan en las zonas francas no escapan al segundo impuesto' con que la protección grava las exportaciones, esto es, la apreciación cambiaria y, en consecuencia, a un mayor costo - comparado con el libre comerciode la mano de obra y de bienes no transables como el transporte local, el espacio industrial, la electricidad, el agua y la eliminación de desechos.

En los últimos diez años, todos los países centroamericanos han promulgado leyes que regulan la creacion de zonas francas. Muchas de estas leyes han modernizado legislación que data de los años setenta, al punto que actualmente ella es bastante similar en los cinco países. El Decreto $\mathrm{N}^{\circ} 46-91$, de Nicatagua, que entró en vigor el 22 de noviembre de 1991, es el cuerpo legal más reciente sobre la materia y reemplaza las leyes promulgadas en la época de Somoza. Algunos países imponen un límite de 8 a 10 años a la exención de los impuestos a las utilidades, pero la disposición pertinente rara vez se hace cumplir. Por lo demás, no podría hacerse cumplir porque las inversiones en actividades de maquila son extremadamente reversibles y en cuestión de semanas un empresario puede cerrar una planta y abrit otra en un lugar diferente sin incurrir en grandes gastos.

Uno de los aspectos que resta atractivo a las zonas francas para los posibles exportadores es el requisito de que las plantas se instalen en enclaves geográficos, cuya ubicación tal vez no sea óptima para la empresa. En esto Costa Rica ha dado muestras de gran flexibilidad, pues permite que los exportadores de la zona franca se trasladen a 'plantas satélites' allí donde la mano de obra es abundante, aunque el lugar esté físicamente distante de la zona tranca. La Ley del régimen de zonas francas y recintos fiscales promulgada en El Salvador en 1990 va más lejos y dispone expresamente que las "empresas que exporten la totalidad de su producción....y que por razones técnicas no están ubicadas en zonas francas podrán solicitar a las autoridades competentes que su establecimiento sea declarado recinto fiscal..." (artículo 20). La ley otorga a los exportadores que operan a partir de recintos fiscales el mismo tratamiento que a los radicados en zonas francas (artículo 22).

\section{Reintegro de los derechos de aduana (admi- sión temporal)}

Los regímenes de admisión temporal tienen una ventaja sobre las zonas francas: permiten que plantas instaladas en cualquier punto del país realicen trabajos de 
montaje o maquila de insumos importados, para exportarlos posteriormente libres de impuestos aduaneros. Esto permite que los posibles exportadores aprovechen Ia infraestructura existente y no necesiten realizar costosas inversiones nuevas. El sistema es similar al de 'recintos fiscales' de El Salvador, pero es más flexible porque permite que las empresas destinen su tiempo (o sus instalaciones) en parte al mercado interno y en parte al mercado de exportación.

La legislación de los cinco países contempla la exoneración de los derechos aduaneros que gravan la maquinaria y los bienes intermedios que se importen con el fin de producir para la exportación. Además, las empresas están exentas del pago de los impuestos a las utilidades ${ }^{7}$ sobre ta proporción de su producción que sea exportada. Los exportadores también pueden pedir la devolución de los impuestos que hayan pagado, pero desde luego esto es más difícil de lograr que la exención. Por esta razón, las empresas que producen tanto para el mercado interno como para la exportación difícilmente podrán utilizar las existencias de que disponen para despachar pedidos de exportación de último minuto. El Salvador es el único de los cinco países que aminora este problema porque permite que las empresas reciban un reintegro general de $6 \%$ (orjginalmente un $8 \%$ ) del valor fob de las exportaciones, en ve $z$ de eximirlas del pago de los derechos de importación y de otros impuestos. ${ }^{8}$ EI problema con Ia tasa de reintegro uniforme es que en el caso de algunos exportadores la devolución es superior al monto de los impuestos pagados, y en otros es inferior.

Gran parte de la industria maquiladora de Costa Rica y Guatemala opera con arreglo al régimen de admisión temporal. Las maquiladoras de los demás países dependen más bien de la legislación rẹativa a zonas francas.

\footnotetext{
${ }^{7}$ En Nicaragua, la exoneración del impuesto sobre las utilidades de las exportaciones es sóto parcial, mientras que en los demás países es total.

${ }^{\mathrm{L}}$ La disposición relativa a la devolución en efectivo de lo pagado por concepto de impuestos entró en vigor en 1990 y favorece tainbién a las exportaciones netas de las empresas que operan con arreglo al régimen de importación temporal. Entre 1986 y 1990, E Salvador otorgó Certificados de Descuento Tributario (CDr) a los exportadores de productos no tradicionales por una suma igual a $30 \%$ del valor de las exportaciones at países no pertenecientes a MCCA, pero en ningún caso superior a los impuestos pagados por los insumos utilizados para producir las exportaciones. Debido a la complejidad de estas normas, pocos exportadores del pais pudjeron hacer uso de los CDT.
}

\section{Los subsidios directos a las exportaciones}

Además de eximir a los exportadores del pago de los impuestos sobre las utilidades y sobre los insumos, los gobiernos suelen otorgarles subsidios directos. Estos rara vez favorecen a los que se dedican a simples labores de montaje o a exportar desde zonas francas. Por lo general se les exige un mínimo de valor agregado de origen nacional.

Los subsidios a las exportaciones no son adecuados como mecanismos para corregir la sobrevaloración del tipo de cambio a que da lugar la protección, porque elevan el precio de las exportaciones expresado en moneda local, pero no el de los insumos importados que se utilizan en el proceso de producción. Por lo tanto, inclinan las exportaciones hacia productos que tienen un elevado contenido de importaciones. Además, inducen a sobrefacturar las exportaciones, tanto para cumplir con el requisito del valor agregado mínimo de origen nacional como para elevar el monto del subsidio.

Cuatro de los cinco gobiernos centroamericanos han subsidiado las exportaciones no tradicionales más allá de Jo que habría correspondido por concepto de devolución de impuestos; ${ }^{9}$ sólo dos, Costa Rica y Nicaragua, siguen haciéndolo en la actualidad, y sus programas al respecto están llegando a su fin. En cada uno de estos casos, los subsidios se han otorgado en forma de certificados de crédito tributario, que los exportadores pueden utilizar para pagar los impuestos o venderlos a terceros con el mismo fín.

El país centroamericano que tiene más experiencia en materia de subsidios directos es Costa Rica. El gobierno comenzó a emitir los llamados certificados de abonos tributarios (CAT) en 1972, pero no los utilizó mucho hasta 1984, año en que empezó a incluirlos en los contratos de exportación a diez años suscritos con empresas calificadas. Al comienzo, los exportadores no tradicionales recibieron los CAT a razón de un $15 \%$ del valor fob de sus ventas a los Estados Unidos $y$ de un $20 \%$ en el caso de las ventas a otros mercados extrarregionales. Los CAT se emiten en moneda local, a su vencimiento (originalmente 12 meses y 18 meses desde 1991) cualquiera puede utilizarlos para pagar los impuestos y se transan libremente en el mercado. La tasa real del subsidio es inferior al $15 \circ 20 \%$, puesto que el valor descontado de los cat es menor que su

\footnotetext{
${ }^{y}$ La excepción es El Salvador, que otorgó créditos tributarios entre 1986 y 1990, pero sólo por el monto de los ímpuestos pagados por los insumos utilizados para fabricar los productos exportados.
} 
valor nominal. Hacia 1992, casi todas las exportaciones no tradicionales de Costa Rica los obtenían. ${ }^{\ddagger 0}$

Para poder recibir certificados de abonos tributarios, las exportaciones deben incorporar un mínimo de $35 \%$ de valor agregado de origen nacional, Sin embargo, de acuerdo con la información disponible, tres de los ocho principales exportadores de Costa Rica los obtuvieron sin haber cumplido con ese requisito (Clark, 1995, p. 198). A partir de 1990, en los nuevos contratos de exportación se redujo la tasa del subsidio, que además disminuía con el tiempo y aumentaba junto con el valor agregado de origen nacional. Desde diciembre de 1992, los contratos de exportación nuevos dejaron de contemplar la entrega de CAT y hacia el año 2000 , Costa Rica habrá puesto fin a su experiencia con esta clase de instrumento.

En los años ochenta, y por un breve período, Guatemala y Honduras otorgaron créditos tributarios a los exportadores de productos no tradicionales. El primero de estos países favoreció con ellos a determinados exportadores, a una tasa uniforme de $10 \%$; el segundo lo hizo a tasas que fluctuaron entre 5 y $15 \%$, según la proporción de valor agregado de origen nacional. Sin embargo, en ambos casos el crédito tributario compensó sólo en parte la amplia y creciente sobrevaloración del tipo de cambio oficial (distinto del valor de equilibrio del mercado), por lo que no estimuló gran cosa las exportaciones. Ambos países dejaron de otorgar créditos tributarios luego de una importante devaluación del tipo de cambio oficial. En Guatemala esto ocurrió en 1986 (año en que el quetzal se devaluó de 1.00 a 2.50 por dolar) y en Honduras en 1990 (cuando el valor de la lempira bajó de 2.00 a 4.20 por dólar). La magnitud de estas devaluaciones compensó con creces a los exportadores por la pérdida del crédito tributario.

En 1992, Nicaragua siguió el ejemplo de Costa Rica y otorgó Certificados de Beneficio Tributario (СBT) por valor de $15 \%$ a los exportadores que cumplían con determinados requisitos. Al igual que en Costa Rica, para tener derecho a ellos los productos debían contener un mínimo de 35\% de valor agregado de origen nacional. Pero, a diferencia de Costa Rica,

\footnotetext{
${ }^{10}$ La principal excepción eran algunas flores, que estaban grovadas por impuestos de contrapartida en los Estados Unidos. En 1992, el valor de las exportaciones subsidiadas por los CAT ascendió a 610 millones de dólares (Clark, 1995, p. 196). De acuerdo con lo que se señala más adelante en el cuadro 3, ese año las exportaciones no tradicionales de Costa Rica a paises no pertenecientes al MCCA ascendieron a 763 millones de dólares, de los cuales 65 millones correspondieron a exportaciones a Panamá, que no reúnen los requisitos para obtener esos certificados, de manera que en 1992 los CAT se emitieron por una cifra cercana al $90 \%$ de las exportaciones no tradicionales a mercados extrarregionales.
}

en 1995 la tasa del subsidio otorgado por Nicaragua a los exportadores se redujo a $10 \%$ y en 1997 bajará a $5 \%$, para finalmente desaparecer en 1998 (en casos excepcionales, el año 2000).

En suma, actualmente sólo Costa Rica y Nicaragua otorgan subsidios directos a las exportaciones. Ambos los están eliminando gradualmente y habrán terminado de hacerlo antes del 2000 . Hasta ahora, poco se ha hablado de mecanismos que podrían reemplazarlos.

\section{Los controles de cambios}

Cuando los bancos centrales mantienen el tipo de cambio en un nivel artificialmente bajo y obligan a las empresas a cambiar en moneda local a ese valor los ingresos que perciben de sus exportaciones, de hecho gravan las exportaciones. Si se obliga a las empresas que operan en las zonas francas a adquirir moneda local al cambio oficial para pagar los salarios y subvenir otros gastos, ni siquiera ellas pueden evitar este 'impuesto'. Cuando el tipo de cambio paralelo se aparta del tipo de cambio oficial, aumenta el control que ejercen los bancos centrales y se tarda en obtener autorización para adquirir divisas con las cuales comprar los insumos necesarios, se hace cada vez más difícil producir para la exportación. A menos que los productores tengan acceso a divisas, la exoneración del pago de los derechos aduaneros que gravan los insumos no incentiva las exportaciones.

Los controles de cambios pueden resultar en un subsidio a las exportaciones no tradicionales, pero es un subsidio costoso y no muy eficaz. Cuando se permite que los exportadores conserven los ingresos que perciben por sus exportaciones (o parte de ellos) y, al mismo tiempo, que paguen los productos que importan al tipo de cambio oficial, el impuesto a las exportaciones puede convertirse en un subsidio a éstas. Si la diferencia entre el tipo de cambio de mercado y el oficial es grande, el subsidio puede llegar a ser muy importante. Supongamos, por ejemplo, que el tipo de cambio oficial es de 2 pesos por dólar y et de mercado de 4 pesos por dólar, y que las exportaciones tienen un contenido de importaciones (libres de impuestos) de $60 \%$. Si el exportador tiene que vender los dólares que reciba a razón de 2 pesos por dólar, ello equivale a gravar el valor agregado con un impuesto de $50 \% . "$ Si se le permite vender dólares a 4 pesos y comprarios a 2 para pagar los insumos importados, el

\footnotetext{
" De cada 100 dólares de exportaciones, 40 corresponden a exportaciones netas. Al tipo de cambio oficial, esto equivale a 80 pesos, es decir, Ja mitad de la suma que podría comprarse al tipo de cambio paralelo.
} 
impuesto de $50 \%$ se transforma en un subsidio de $75 \% .^{12} \mathrm{El}$ subsidio no es muy eficaz por dos razones. Primero, lo más probable es que el empresario piense que esta situación será transitoria y, en consecuencia, no haga inversiones para aumentar sus exportaciones. Segundo, para comprar divisas al reducido precio de 2 pesos por dólar seguramente habrá que incurrir en demoras y gastos de tipo burocrático.

Aparte de eliminar toda clase de controles, una de las maneras de evitar que los controles de cambio se conviertan en un impuesto inadvertido sobre las exportaciones no tradicionales es permitir que los exportadores conserven las divisas que perciben y que com-

\section{III}

\section{Los resultados}

Los efectos de las medidas de fomento de las exportaciones aplicadas en los países centroamericanos figuran en los gráficos 1,2 y 3 , que muestran el valor de las exportaciones no tradicionales, excluida la maquila, correspondientes a cada uno de estos países. Todos los datos se expresan en dólares corrientes y no se ha intentado hacer ajustes por concepto de inflación. Los datos completos, incluidos los de las exportaciones tradicionales se muestran en el cuadro 3. En los gráfi-

GRAFICO I

Centroamérica: Exportaciones no tradicionales

(Millones de dólares)

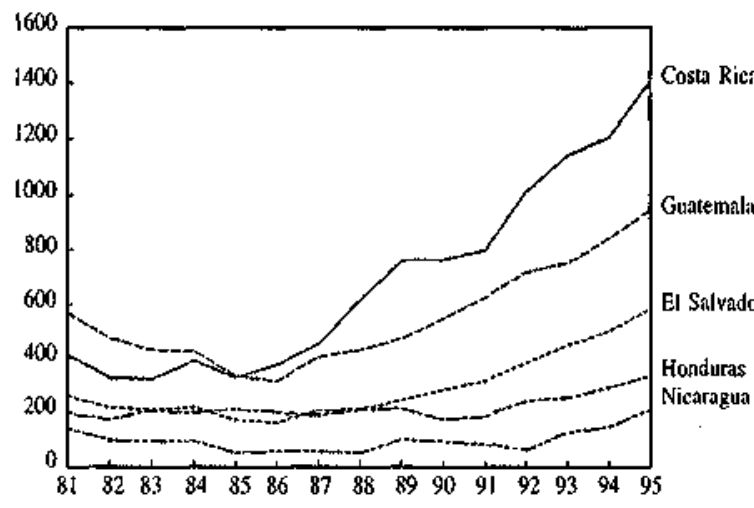

a Excluye la maquila

12 Por cada 100 dólares exportados, las exportaciones netns siguen siendo 40 dólares, pero los ingresos netos que percibe el exportador son iguales a $400-120=280$ pesos y $280 / 160=1.75$. pren moneda local en el mercado paralelo. Actualmente, es el sistema que aplican los cinco países, pero en el pasado no siempre fue así. Más de una vez, todos los bancos centrales de la región han establecido controles cambiarios en virtud de los cuales han existido tipos de cambio múltiples. No corresponde examinar aquí esta trayectoria y sus efectos en las exportaciones, lo que además quizá esté al margen de las posibilidades del autor. Baste con señalar que el temor a una reversión de la política, al regreso a los controles de cambios del pasado, disminuye la eficacia de los incentivos que se otorgan a las exportaciones en el presente.
GRAFICO 2

Centroamérica: Exportaciones al Mercado Común Centroamericano (Millones de doilares)

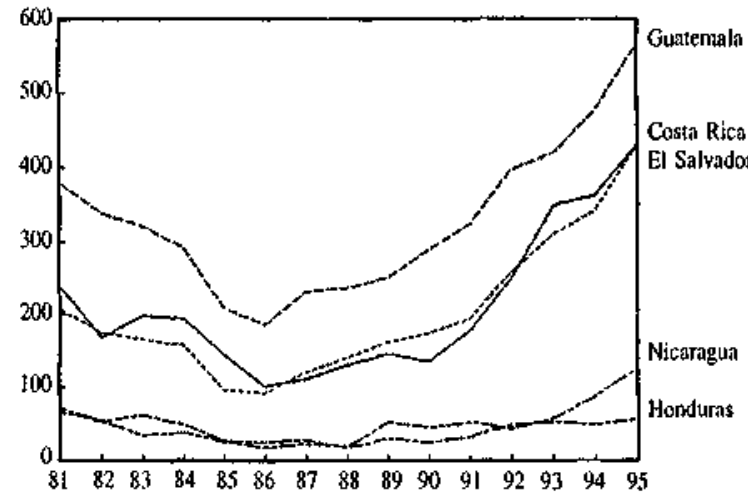

GRAFICO 3

Centroamérica: Exportaciones no tradicionales ${ }^{\circ}$ at resto del mundo (Millones de dolares)

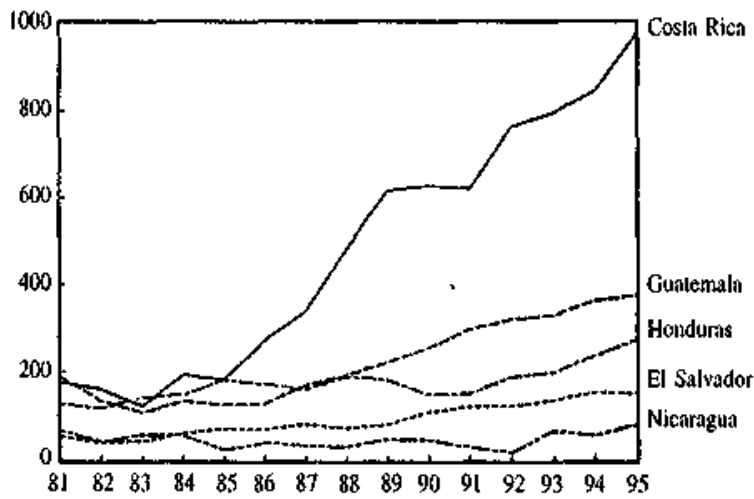

a Excluye la maquila 
Centroamérica: Exportaciones tradicionales y no tradicionales, 1981-1995*

(Millones de dólares)

\begin{tabular}{|c|c|c|c|c|c|c|c|c|c|c|c|c|c|c|c|}
\hline & 1981 & 1982 & 1983 & 1984 & 1985 & 1986 & 1987 & 1988 & 1989 & 1990 & 1991 & 1992 & 1993 & 1994 & 1995 \\
\hline \multicolumn{16}{|l|}{ Costa Rica } \\
\hline Total exportaciones & 1002.6 & 869.0 & 852.5 & 997.5 & 939.1 & 1084.9 & 1106.7 & 1245.7 & 414.6 & 1448.2 & 1597.7 & 1 851.1 & 2094.7 & 2258.5 & 2624.1 \\
\hline $\begin{array}{l}\text { Tradicionales } \\
\text { No tradicionales: }\end{array}$ & 587.4 & 40.7 & 530.3 & 608.7 & 611.1 & 711.4 & 657.8 & 630.7 & 654.4 & 684.5 & 797.5 & 839.4 & 951.7 & 1054.2 & 1221.7 \\
\hline Al MCCA & 238.0 & 167.2 & 198.2 & $193: 0$ & 143.5 & 100.5 & 109.8 & 129.9 & 144.1 & 134.6 & 177.8 & 248.4 & 348.3 & 360.7 & 427.6 \\
\hline Al resto del mundo & 177.2 & 161.1 & 124.0 & 195.8 & 184.5 & 273.0 & 339.1 & 485.1 & 616.1 & 629.1 & 622.4 & 763.3 & 794.8 & 843.6 & 974.8 \\
\hline \multicolumn{16}{|l|}{ El Salvador } \\
\hline Total exportaciones & 798.0 & 699.6 & 757.9 & 725.9 & 695.1 & 754.9 & 590.9 & 608.8 & 497.8 & 581.5 & 588.0 & 597.5 & 742.0 & 818.9 & 1004.6 \\
\hline Al MCCA & 206.5 & 174.2 & 164.9 & 157.2 & 95.7 & 91.0 & 119.6 & 139.8 & 160.6 & 173.0 & 193.7 & 257.3 & 309.2 & 340.4 & 426.6 \\
\hline Al resto del mundo & 53.5 & 41.0 & 44.0 & 60.8 & 71.9 & 69.6 & 82.9 & 73.1 & 81.1 & 110.2 & 122.2 & 123.0 & 136.9 & 154.5 & 152.4 \\
\hline \multicolumn{16}{|l|}{ Guatemala } \\
\hline Total exportaciones & 1291.4 & 1170.4 & 1091.7 & 1132.2 & 1059.7 & 1043.8 & 977.9 & 1073.4 & l 126.1 & 1211.5 & 1230.0 & 1283.6 & 1363.2 & 1550.2 & 1988.8 \\
\hline $\begin{array}{l}\text { Tradicionales } \\
\text { No tradicionales }\end{array}$ & 721.8 & 697.9 & 661.9 & 706.6 & 725.3 & 730.7 & 575.7 & 642.5 & 653.6 & 666.0 & 606.3 & 566.9 & 613.7 & 710.7 & 1046.0 \\
\hline Al MOCA & 378.9 & 337.3 & 320.9 & 291.4 & 207.8 & 185.3 & 230.6 & 236.4 & 248.9 & 288.2 & 324.0 & 395.4 & 417.8 & 475.0 & 565.4 \\
\hline Al resto del mund & 190.7 & 135.2 & 108.9 & 134.2 & 126.6 & 127.8 & $17 \mathrm{t} .6$ & 194.5 & 223.6 & 257.3 & 299.7 & 321.3 & 331.7 & 364.5 & 377,4 \\
\hline Total exportaciones & 753.6 & 676.5 & 698.7 & 737.1 & 789.6 & 891.3 & 844.3 & 893.0 & 868.4 & 831.0 & 792.4 & 801.3 & 808.0 & 872.8 & 1092.0 \\
\hline $\begin{array}{l}\text { Tradicionales } \\
\text { No tradicionales: }\end{array}$ & 560.1 & 506.1 & 494.0 & 540.6 & 580.1 & 693.6 & 658.2 & 685.2 & 657.0 & 659.0 & 608.4 & 563.1 & 556.1 & 585.7 & 760.9 \\
\hline Al MCCA & 65.9 & 51.9 & 61.3 & 47.7 & 25.5 & 23.4 & 25.9 & 15.7 & 28.9 & 22.9 & 32.0 & 48.2 & 51.4 & 47.2 & 55.0 \\
\hline Al resto del mundo & 127.6 & 118.5 & 143.4 & 148.8 & 184.0 & 174.3 & 160.2 & 192.1 & 182.5 & 149.1 & 152.0 & 190.0 & 200.5 & 239.9 & 276.1 \\
\hline \multicolumn{16}{|l|}{ Nicaragua } \\
\hline Total exportaciones & 513.8 & 408.6 & 451.9 & 412.4 & 305.1 & 257.2 & 295.0 & 235.7 & 310.7 & 330.6 & 272.4 & 223.1 & 267.0 & 351.2 & 497.3 \\
\hline $\begin{array}{l}\text { Tradicionales } \\
\text { No tradicionales: }\end{array}$ & 375.6 & 313.3 & 360.1 & 318.6 & 256.1 & 200.8 & 239.9 & 185.6 & 211.9 & 239.6 & 190.8 & 162.5 & 142.6 & 208.6 & 291.9 \\
\hline Al MCCA & 70.8 & 52.1 & 33.5 & 37.0 & 24.2 & 15.5 & 20.5 & 17.9 & 50.6 & 43.7 & 51.2 & 41.7 & 56.8 & 86.6 & 123.3 \\
\hline Al resto del mundo & 67.4 & 43.2 & 58.3 & 56.8 & 24.8 & 40.9 & 34.6 & 32.2 & 48.2 & 47.3 & 30.4 & 18.9 & 67.6 & 56.0 & 82.1 \\
\hline
\end{tabular}

Fuente: Consejo Monetario Centroamericano.

a No comprende las exportaciones de maquila. Las exportaciones tradicionales incluyen café, azúcar y carne respecto de los cinco países, más bananos, productos de mar y cacao en Costa Rica; algodón y productos de mar en El Salvador; bananos, algodón, cardamomo y petróleo en Guatemala: bananos, algodón, productos de mar y madera en Honduras; bananos, algodón y productos de mar en Nicaragua. 
$\cos 2$ y 3 , así como en el cuadro 3 , se distingue entre las exportaciones destinadas al MCCA y las que van al resto del mundo. Esto se hace por dos razones. Primero, sólo las exportaciones extrarregionales se benefjcian de la exención de impuestos y de subsidios directos, ya que los mecanismos que ordinariamente se consideran como incentivos para promover las exportaciones no tradicionales no se aplican a las exportaciones a países miembros del MCCA. Segundo, el valor de las exportaciones al MCCA se expresa en precios centroamericanos protegidos, mientras que el valor de las exportaciones al resto del mundo corresponde en su mayor parte a los precios internacionales. En otras palabras, el valor de las exportaciones a los paises del MCCA incluye un subsidio implícito pagado por el importador, mientras que el valor de la mayoría de las exportaciones al resto del mundo no lo incluye.

De los cinco países centroamericanos, el que ha tenido el desempeño exportador más notable es Costa Rica. En efecto, el valor de sus exportaciones no tradicionales se elevó de 328 millones de dólares en 1985 a I 403 millones en 1995, con lo que sobrepasó a Guatemala como principal exportador centroamericano. Casi todo el incremento corresponde a exportaciones fuera del MCCA (incluso al país vecino de Panamá), puesto que en el mismo período las exportaciones a los demás miembros del MCCA aumentaron menos de 300 millones de dólares. Este resultado no es sorprendente, ya que sólo en Costa Rica se otorgaron subsidios directos (los CAT) a las exportaciones fuera de la región. Cabe preguntarse si la forma en que reaccionaron las exportaciones compensó el costo de los subsidios. El Gobierno de Costa Rica llegó a la conclusión de que no, razón por la cual está eliminando gradualmente el programa.

En Costa Rica, la discusión se ha centrado en el elevado costo fiscal del programa de subsidios, que en 1.989 ascendio a un $1.2 \%$ del PtB. ${ }^{13}$ En cambio, no parece haber preocupación por el costo económico que tienen para los consumidores las importaciones desde

\footnotetext{
${ }^{1.3}$ Los costarticenses también se laan quejado de la corrupción (sobrefacturación de las exportaciones) y de que un número reducido de exportadores ha acaparado los beneficios. En los 18 meses transcurridos entre julio de 1988 y diciembre de 1989 , un 10\% de los car favoreció a una sola empresa (PNDECO, filial productora de piña de la Del Monte) y las 26 empresas más grandes, inclujida la PINDECO, absorbieron un 51\% de los CAT (Clark, 1995, p. 198). Sin embargo, en ese período se otorgaron CAT por la casi totalidad de las exportaciones no tradicionales, por lo que seguramente la concentración de los beneficios corresponde a economías de escala de las exportaciones y no a que se haya discriminado contra los exportiơores pequef̂os.
}

los países miembros del MCCA que, recíprocamente, subsidian las exportaciones de Costa Rica a dicha agrupación regional.

¿Cómo reaccionaron los exportadores de Costa Rica a los subsidios en CAT? Para responder a esta pregunta hay que estimar lo que habría sido el volumen de las exportaciones de no haber sido por los subsidios. Hoffmaister (1992), en el único estudio de esta naturaleza disponible sobre Costa Rica, utilizó las es. tadísticas trimestrales correspondientes al período 1970-1989 para estimar el siguiente modelo de regresión:
volumen de las exportaciones $=$ función de (subsidios en CAT, precios relativos, tipo de cambio nominal, pre real\}.

En este modelo la variable dependiente es el volumen de todas las exportaciones de productos no tradicionales, incluidas la maquila y las exportaciones intrarregionales, dos categorías que en ningún momento reunieron los requisitos para que se les otorgaran subsidios en forma de CATs. ${ }^{14}$ Los precios relativos se definen como "el precio mundial relativo de las exportaciones en función del precio interno", y el tipo de cambio nominal como el precio de las divisas. El producto interno bruto real se refiere a Costa Rica, de manera que el modelo es uno de oferta más que de demanda de exportaciones. ${ }^{15}$

Tras estimar el modelo y examinar su desempeño como intrumento de pronóstico, Hoffmaister procedió a simular las exportaciones realizadas a partir de 1984, para lo cual fijó en cero los subsidios en CaT en el período 1984-1989 (hasta 1984 prácticamente no se otorgaron subsidios). A continuación, comparó las exportaciones reales con las exportaciones simuladas en ese mismo período y encontró que en esos seis años las primeras sólo superaron a las segundas en $10 \%$ (esto es, en 277 millones de dólares). En el mismo período se otorgaron subsidios en car por valor de 205

\footnotetext{
${ }^{14} \mathrm{El}$ volumen de las exportuciones se calculó dividiendo el valor de las exportaciones por el índice de precios de las exportaciones no tradicionales. La maquila constituyó una proporción pequeña aunque creciente de las exportaciones no tradicionales, y en 1989 representó un $9.5 \%$ de éstas (Hoffmaister, 1992, p. 154, nota 19). ${ }^{15}$ De todas formas, en el caso de las economías pequeñas, el PIB de los mercados de destino no debería ser un factor determinante de las corrientes de exportaciones. Webb y Fackler (1993) comprobaron que, en el periodo comprendido entre 1955 y 1980 , esto era efectivo respecto de las exportaciones de Costa Rica al resto del MCCA, a los países industrializados del norte y a los paises en desatrollo del sur.
} 
millones de dólares, de modo que en promedio cada dólar de subsidio sólo habría aumentado las exportaciones en 1.35 dólares. En 1988 y 1989 el contenido de importaciones de las exportaciones no tradicionales costarricenses fue estimado en $60 \%$, lo que signifíca que cada dólar de subsidio aumentó las importaciones en 81 centavos de dólar y las exportaciones netas en sólo 54 centavos: esto indica un pasmoso derroche del dinero de los contribuyentes. Las exportaciones respondieron en forma igualmente poco dinámica a las otras dos variables de los precios (los precios relativos y el tipo de cambio nominal). ${ }^{16}$

En suma, el modelo de Hoffmaister no atribuye mucho del notable desempeño de las exportaciones de Costa Rica al hecho de que los subsidios en CAT, los precios relativos o el tipo de cambio hayan sido favorables. En cambio, el coeficiente que corresponde a la variable de escala (PJB real) es muy elevado, ya que por cada punto porcentual de incremento del producto real, e] volumen de las exportaciones aumenta más de $2 \%$. En este modelo, la razón entre las exportaciones y el PIB se eleva rápidamente a través del tiempo, independientemente de lo que suceda con los precios. La tendencia se mantiene en el período de simulación, en que se fija una tasa de subsidio igual a cero. El supuesto implícito es que la tasa de crecimiento de las exportaciones babría duplicado con creces la de crecimiento del PIB, aun sin los certificados de abonos tributarios.

Estas conclusiones podrían interpretarse como prueba de que los incentivos de precios no influyen mucho en las decisiones de los empresarios centroamericanos, pero esta conclusión es prematura, por dos razones. Ante todo, el modelo de Hoffmaister pasa por alto dos variables importantes, a saber, el tipo de cambio paralelo y el acceso de los exportadores al mercado paralelo, y es bien sabido que un error de esta naturaleza en las especificaciones produce un sesgo en las estimaciones de los coeficientes de todas las variables consideradas. ${ }^{17}$ Segundo, no se dispone de estadísticas trimestrales de las exportaciones por países de desti-

${ }^{16}$ El cálculo de la elasticidad (variación porcentual del volumen de exportaciones que va unida a la variación de un punto porcentual zn el precio de las exportaciones) fue de 0.18 en el caso de los subsidios en certificados de abonos tributarios, de 0.23 en el de los precios relativos y de 0.13 en el del tipo de cambio nominal. No se judo rechazar la hipótesis nula de que las tres elasticidades son guales. En cambio, el coeficiente de la variable de escala (plB real) üe de 2.3I (véase Hoffmaister, 1992, pp. 155- 156). Es extremadamente inusual que el Fondo Monetario Internacional publique estuidios que contengan esta clase de conclusiones, esto es, ique los precios influyen poco en la oferta de exportaciones!

${ }^{7}$ El tipo de cambio nominal incluido por Hoffmaister en su modelo es fijado por el Banco Central de Costa Rica y rara vez es un no, por lo que Hoffmaister debió basar su modelo en las exportaciones totales. Lo más probable es que la introducción de subsidios a las exportaciones fuera de la región estimule a los productores a enviar sus productos a mercados distantes y no a Centroamérica y Panamá. ${ }^{18}$ La reducción de los aranceles que se aplican en el MCCA, e incluso la posibílidad de que ellos bajen, puede tener el mismo efecto, esto es, hacer que los mercados extrarregionales resulten más atractivos que los de la región. Es posible que la falta de dinamismo de la reacción a los subsidios, que comprobó Hoffmaister en el caso de las exportaciones totales, ocuite una marcada reacción positiva cuando se trata de exportaciones extrarregionales y una negativa si ellas son intrarregionales.

En cuanto a las exportaciones de Costa Rica, se dispone de estadísticas anuales pormenorizadas, pero el reducido número de observaciones impide estimar un modelo econométrico mediante las técnicas de cointegración que se utilizan rutinariamente para las estimaciones derivadas de observaciones de series de tiempo. Además, hay otro problema y es que lasi estadísticas relativas a las exportaciones no tradicionales se expresan en dólares de valor nominal. Lo ideal sería deflactarlas por un índice de precios, pero el problema es determinar cuál. Cabe preguntarse si es adecuado utilizar un solo índice tanto para el comercio intrarregional como para el extrarregional. A fin de evitar estas dificultades, he dividido el valor de las exportaciones por el PIB nominal, convertido a dólares de los Estados Unidos al tipo de cambio de mercado. Este método también plantea problemas, pero como primera aproximación se presta para estudiar los efectos de los subsidios a las exportaciones costarricenses.

El gráfico 4 muestra las exportaciones no tradi-

valor de equilibrio del mercado. El exceso de demanda de divisas se refleja en un sobreprecio de ellas en transacciones en el mercado paralelo. Este sobreprecio tiende a ser mayor precisamente cuando la combinación de subsidios, precios relativos y tipo de cambio nominal es menos favorable a las exportaciones, esto es, cuando es inminente que se produzca una devaluación importante. Si se permite que los empresarios cambien la totalidad o parte de sus entradas en divisas en el mercado paralelo, como a menudo sucede en Costa Rica, Jas exportaciones pueden prosperar inctuso cuando las señales de los precios parezcan ser negativas.

IR Para un intento de medir este cambio de orientación del MCcA hacia los mercados extrarregionales inducido por los subsidios en Nicaragua, vease Tello (1996). Willmore $(1989$, p. 60) describe la creciente semejanza que se observa en las exportaciones intrarregionales y extrarregionales de manufacturas del MCCA en los años setenta y ochenta, la que facilita los cambios de destino de las exportaciones no tradicionales. 
cionales de Costa Rica (excluida la actividad maquiladora) como porcentaje del PIB, en el período comprendido entre 1970 y 1995. En 1984 se introdujeron los contratos de exportación, acompañados de subsidios en certificados de abonos tributarios de modo que el período hasta 1983 se puede utilizar para medir la tendencia del coeficiente de las exportaciones en esa fecha. ${ }^{19}$ Esta tendencia lineal es una ecuación de pronóstico muy elemental y su pendiente es sensible a la inclusión o exclusión de los dos primeros años (1970 y 1971). Sin embargo, la proyección de la tendencia del período 1970-1983 al período 1984-1995 sirve para ilustrar el modelo más complejo de Hoffmaister, ya que los coeficientes de cada una de sus variables de precios son bastante bajos. ${ }^{20}$ Nótese que, en promedio, la razón de las exportaciones reales del período posterior a 1984 difiere muy poco de la tendencia proyectada: hasta 1987 las exportaciones reales fueron inferiores a la tendencia de las exportaciones y a partir de 1988 se situaron por encima de la tendencia. La proyección de las exportaciones, de manera muy similar a lo sucedido con las exportaciones reales, se elevó de $8 \%$ del pIB en 1970 a casi $14 \%$ en 1995 . En general, de acuerdo con esta medida, en el período 1984-1995, y como reacción a los subsidios, las exportaciones sólo aumentaron 286 millones de dólares, es decir, menos de $3.5 \%$ de las exportaciones reales. Naturalmente, esto es en el supuesto de que la tendencia positiva de la razón entre las exportaciones y el PIB que se registró en el período 1970-1983 se hubiera mantenido aunque no hubiese existido el programa de certificados de abonos tributarios.

Cabe preguntarse hasta qué punto tal programa influyó en las exportaciones intrarregionales. Los datos pertinentes figuran en el gráfico 5. También en este caso se ajusta una tendencia lineal a las observaciones correspondientes al período $1970-1983$, y se proyecta a los años posteriores. ${ }^{21}$ Las exportaciones intrarregionales disminuyen marcadamente, mientras que la tendencia proyectada resulta positiva. Por lo que respec-

14 La línea de tendencia del período 1970-1983 que figura en el gráfico 4 es $100^{*}$ exportaciones/PIB $=7.89+0.23 t, R^{\wedge} 2=0.152$, $D W=1.09$. La variable $t$ (tiempo) tiene el valor de la unidad en 1970, y de ah́ en adelante aumenta en uno todos los años.

${ }^{20}$ Más exactamente, la estimación de la oferta de exportaciones resulto ser un valor muy inekástico respecto del precio, con coefi. cientes de 0.13 a 0.23 (Hoffmaister, 1992, p. 155).

${ }^{21} \mathrm{La}$ línea de regresión que figura en el gráfico 5 es $100^{*}$ exportaciones $/ \mathrm{PI}=4.61+0.24 t, R^{\wedge} 2=0.408, D W=1.83$
GRAFICO 4

Costa Rica: Exportaciones no tradicionales (Porcentaje del producto interno bruto)

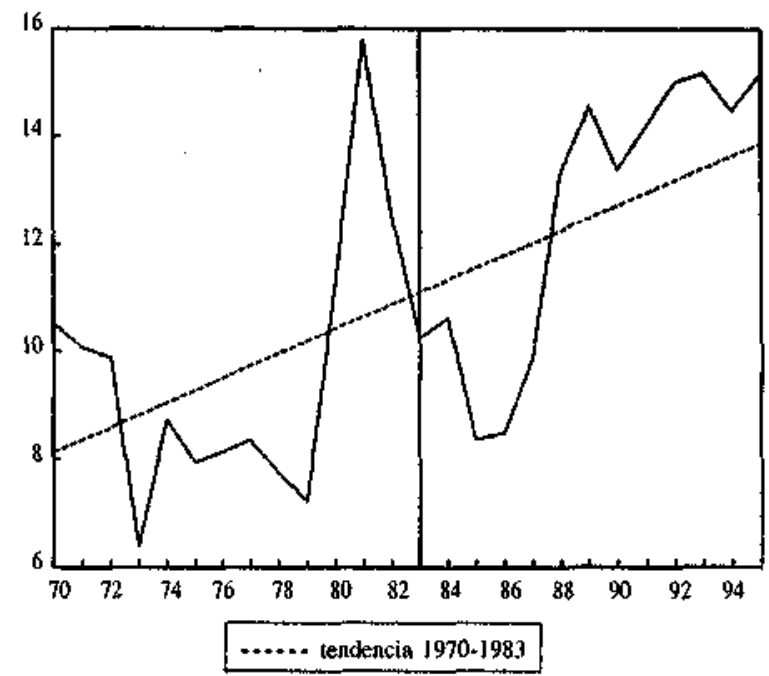

"Excluye ta maquila

GRAFICO 5

Costa Rica: Exportaciones a Centroamérica y Panamá

(Porcentaje del producto interno bruto)

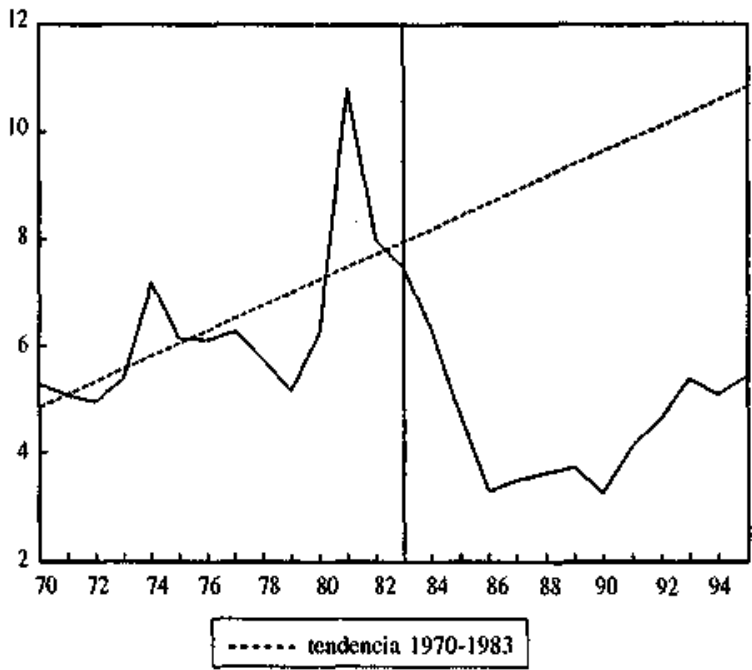

ta al período 1984-1995 en su conjunto, las exportaciones reales sólo alcanzaron a 3137.8 millones de dólares, lo que representa un déficit de 3686.4 millones, puesto que de acuerdo con las proyecciones deberian haber llegado a 6824.2 millones.

Como puede verse en el gráfico 6, en las exportaciones al resto del mundo el resultado es justo lo contrario: prácticamente no se proyecta una tendencia, 
GRAFICO G

Costa Rica: Exportaciones no tradicionales al resto del mundo

(Porcentaje del producto interno bruto)

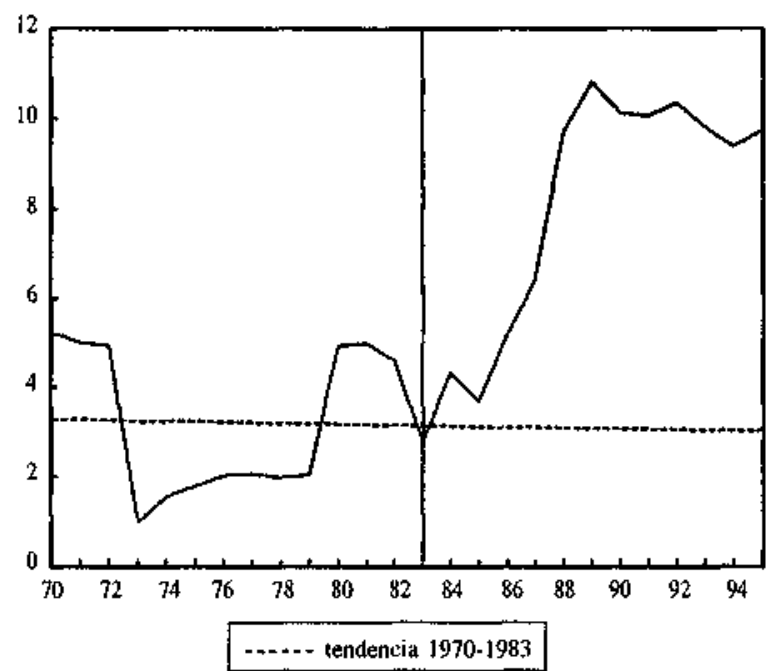

a Excluye la maquila.

pese a lo cual las exportaciones reales aumentan. ${ }^{22} \mathrm{La}$ serie alcanza su punto máximo en 1989 , cuando llega a $10.9 \%$, y comienza a declinar en 1990 , precisamente el año en que los subsidios en certificados de abonos tributarios se redujeron. Por lo que respecta al período 1984-1995 en su conjunto, las exportaciones extrarregionales reales superaron el valor proyectado en 3992.7 millones de dólares. En cuanto al período 1984-1989 examinado por Hoffmaister, de acuerdo con esta medida las exportaciones extrarregionales respondieron por valor de 1026 millones de dólares, esto es, 3.70 dólares por cada dólar de subsidio en cerficados de abonos tributarios.

A juzgar por esta proyección elemental de las tendencias anteriores a 1984, parece que gran parte del incremento de las exportaciones extrarregionales de Costa Rica se contrarrestó con una disminución de los embarques a Centroamérica y Panamá, no aptos para recibir subsidios en tales certificados. Por otra parte (véase una vez más el gráfico 2), en el período 19841995 Costa Rica logró conservar su posición relativa en las exportaciones dentro del MCCA, de modo que los incentivos otorgados a las exportaciones extrarregionales tal vez no hayan influido gran cosa en las expor-

${ }^{22}$ La línea de regresión de la tendencia correspondiente al periodo 1970-1983, que figura en el gráfico 6, es $100^{*}$ expottaciones/PIs $=$ $3.28-0.01 t, R^{\wedge} 2=0.001, D W=0.82$. taciones intrarregionales. Para realizar proyecciones $e x$ ante razonablemente confiables de las exportaciones se necesitan modelos mejores, estimados a partir de datos desagregados. Por desgracia, la experiencia recogida de investigaciones anteriores es negativa: los resultados obtenidos por Hoffmaister tienen fallas porque no se distinguió entre las exportaciones aptas para recibir subsidios y aquellas que no reúnen los requisitos necesarios. Las técnicas econométricas de diseño avanzado no pueden suplir la inadecuada agregación de los datos subyacentes.

En su balanza de pagos los gobiernos centroamericanos generalmente han incluido la maquila en los servicios, aunque están empezando a incluirla en las exportaciones e importaciones de mercancías. Las cuentas nacionales no contemplan una partida separada para esta actividad, de modo que hay escasas estadísticas históricas sobre la industria maquiladora: por extraño que parezca, se sabe más sobre el empleo en ella que sobre sus exportaciones brutas o netas. $\mathrm{El}$ cuadro 4 contiene estimaciones del empleo en la maquila alrededor de 1995 y muestra que, salvo en $\mathrm{Ni}$ caragua, esta actividad pasa por un período de bonanza.

No me canso de insistir en la necesidad de incluir la maquila dentro de las exportaciones no tradicionales de la región. Es lamentable que no haya estadísticas comerciales disponibles sobre la actidad maquiladora para todos los años y todos los países. Los programas de investigación de quienes se ocupan del comercio y el desarrollo en la región deberían asignar una alta prioridad a la recopilación de estos datos. Por ejemplo, informaciones proporcionadas por El Salvador indican que en 1995 las exportaciones brutas de

CUADRO 4

Centroamérica: Empleo en la Industria maquiladora, alrededor de 1995

(Nümero de personas empleadas)

\begin{tabular}{lr}
\hline Costa Rica & 50000 \\
El Salvador & 50000 \\
Guatemala & 80000 \\
Honduras & 48000 \\
Nicaragua & 7000 \\
Total & 235000 \\
\hline
\end{tabular}

Fuente: The Economist Intelligence Unit, Country Reports, salvo respecto de Costa Rica.

a Estimación del autor, teniendo en cuenta que la actividad maquiladora para exportación a los Estados Unidos es tan importante en Costa Rica como en Honduras o Guatemala.

b $79 \%$ de mujeres.

c $81 \%$ de mujeres, según estimaciones de 1992. 
maquila ascendieron a 656.7 millones de dólares, cifra que sobrepasa el valor de todas las demás exportaciones no tradicionales de ese año y más que cuadruplica el valor de las exportaciones no tradicionales realizadas por empresas salvadoreñas fuera de Centroamérica. Dos años antes, en 1993, el valor de las exportaciones salvadoreñas de maquila sólo alcanz6 a 290 millones de dólares, pese a lo cual duplicó el valor de otras exportaciones no tradicionales a mercados extrarregionales. ${ }^{23}$

Ocho o nueve años atrás, la industria maquiladora de la región era casi inexistente. En 1989, en El Salvador la maquila sólo daba empleo a 4200 personas, cifra que se elevó a 50000 en 1995 y a 62000 en 1996. En Honduras, el número de trabajadores aumentó de 9000 en 1990 a 20000 en 1991 y a 48000 en 1995. $\mathrm{Al}$ parecer, en Guatemala el empleo en la actividad maquiladora no ha aumentado gran cosa en los últimos años, en circunstancias que en 1992 registró cifras nada despreciables. En realidad, de acuerdo con las informaciones, cuando terminó la guerra civil en El Salvador algunos de Jos maquiladores guatemaitecos se trasladaron a ese país.

En 1995 la industria maquiladora dio empleo a cerca de 235000 personas en la región (véase otra vez el cuadro 4). Esta citra resulta muy notable si se considera que en esa misma época tas zonas francas bien establecidas de la República Dominicana sólo empleaban a 176000 personas (Willmore, 1995). Tanto en Centroamérica como en la República Dominicana, la maquila se concentra en la fabricación de prendas de vestir para exportar a los Estados Unidos, de manera de aprovechar las cuotas por países. Sin embargo, también abarca otras actividades, como programas de informática en Costa Rica y procesamiento de datos en El Salvador.

\section{IV}

\section{Resumen y conclusiones}

De igual manera que el resto de América Latina, Centroamérica tiene una trayectoria de 'desarrollo hacia adentro' al amparo de barreras comerciales. La creación del Mercado Común Centroamericano en 1960 no interrumpió el proceso sino que, por el contrario, al aumentar los aranceles, lo aceleró. Dentro del MCCA los productos se transan libremente, pero están protegidos de la competencia externa, de modo que al pagar precios más altos que los que se cotizan en el mercado mundial, los consumidores de cada uno de los países de la región subsidian algunas de las exportaciones de los países asociados. También subsidian a los productores de sus propios países cuando compran productos locales a precios protegidos. Salvo por la ausencia de trámites burocráticos, es como si los gobiernos gravaran el consumo de determinados bienes y destinaran lo recaudado a otorgar subsidios precisamente a quienes producen estos bienes, sea cual fuere el lugar en que estén radicados dentro del MCCA.

La protección induce a los productores centroamericanos a sustituir las importaciones provenientes del

${ }^{23}$ Estos datos corresponden al Banco Central de Reserva de El Salvador que, por desgracia, no tiene cifras relativas a los años anteriores a 1993. resto del mundo; al mismo tiempo, las barreras arancelarias desalientan las exportaciones debido al aumento de valor de los bienes intermedios protegidos y a la sobrevaloración de las monedas locales en comparación con los tipos de cambio de libre comercio. A partir de mediados de los años ochenta, los gobiernos centroamericanos comenzaron seriamente a reducir este desincentivo de las exportaciones y a compensarlo de diversas maneras. Primero, disminuyeron marcadamente el arancel que gravaba las importaciones. Segundo, permitieron que los exportadores accedieran a los bie nes intermedios a precios internacionales, permitiéndoles operar desde zonas francas o con arreglo a regímenes de admisión temporal. Tercero, fijaron el tipo de cambio al valor de equilibrio del mercado o a uno proximo a éste, y terminaron por eliminar totalmente los controles de cambios, al menos para los exportadores. Dos de los cinco países, Costa Rica y Nicaragua, otorgaron subsidios directos adicionales a las exportaciones no tradicionales destinadas a los mercados extrarregionales.

Las exportaciones no tradicionales de Costa Rica son las que mejor han respondido a esta modificación de la política comercial que favorece las exportaciones al otorgarles los subsidios más generosos. Sin em- 
bargo, tal vez los subsidios directos hayan sido más eficaces para inducir a los exportadores a trasladarse de los mercados regionales a los extrarregionales que para promover el incremento de las exportaciones. Si esto fuera así, o se creyera que lo es, no debe extrañar que Costa Rica desee poner fin a su programa de subsidios directos a las exportaciones. Desde el punto de vista del interés nacional, no tiene sentido que Costa Rica subsidie con dinero de los contribuyentes exportaciones que de lo contrario serían subsidiadas por los consumidores de otros países de la región.

Por otra parte, desde el punto de vista regional, el otorgamiento de subsidios directos a las exportaciones no tradicionales es perfectamente razonable, aunque induzca a los exportadores a preferir los mercados de ultramar, siempre que estos subsidios no sean superiores al subsidio implícito (esto es, a la protección) que va incluido en el precio de las exportaciones intrarregionales. Para asegurar que todos los países se beneficien, el programa de subsidios debe ser uniforme en toda la región. La necesidad de un subsidio común a las exportaciones se asemeja a la necesidad de un arancel externo común: del mismo modo que si el arancel de importación es superior al arancel común los altos precios pagados por las exportaciones de un país asociado pueden dar lugar a pérdidas, si el subsidio a las exportaciones es superior al nivel común pueden producirse pérdidas al incentivar a los exportadores a vender en los mercados extrarregionales en vez de los intrarregionales.

Por lo general, los insumos importados que se utilizan para producir exportaciones extrarregionales están exentos del pago de derechos aduaneros, de modo que es también importante subsidiar las exportaciones netas y no las exportaciones brutas; de lo contrario, los incentivos obran en favor de las exportaciones que tienen un alto contenido de importaciones. A menudo se sostiene que es preciso subsidiar las exportaciones porque los salarios son elevados, ta productividad baja, la infraestructura deficiente, la administración pública ineficiente, la salud pública y la educación deficientes, etc. Todos estos argumentos son falsos, puesto que estas ineficiencias y distorsiones afectan a toda la economía y no sólo al sector exportador. Lo único que justifica los subsidios a las exportaciones es la protección ante las importaciones. Por esa razón, los subsidios a las exportaciones nunca deberían ser superiores al grado que constituye protección contra las importaciones. A menos que las importaciones estén gravadas por aranceles o sujetas a cuotas, no hay razón para subsidiar las exportaciones.

El Salvador, Guatemala y Honduras no han tenido tanto éxito como Costa Rica en el fomento de las exportaciones y como no subsidian directamente las exportaciones extrarregionales, siguen dependiendo más del mercado regional. En Centroamérica, la promoción de las exportaciones ha dado mejores resultados de lo que sugieren las estadísticas del comercio de productos básicos, porque en ellas se excluye la maquila que, salvo en Nicaragua, es muy importante. En este último país, los incentivos a las exportaciones comprenden la unificación del tipo de cambio, el acceso a insumos intermedios a precios internacionales y una versión menos generosa de los subsidios directos que se otorgan en Costa Rica. Hasta ahora, las exportaciones nicaragüenses han respondido con escaso dinamismo, pero el programa sólo comenzó a aplicarse en 1992.

(Traducido del inglés)

\section{Bibliografía}

Bhagwatti, J. y V.K. Ramaswami (1963): Domestic distortions, tariffs, and the theory of optimum subsidy, Journal of Political Economy, vol. 7t, $\mathrm{N}^{\circ}$ 1, Chicago, Illinois, The University of Chicago Press, febrero.

Caves, R.E. y R.W, Jones (1973): World Trade and Payments: An Introduction, Boston, Massachusets, Little, Brown and Company.

Clark, M.A. (1995): Non-traditional export promotion in Costa Rica: Sustaining export-led growth, Journal of Interamerican Studies and World Affairs, vol. $37, \mathrm{~N}^{\circ} 2$, Beverly Hills, California, University of Miami, verano.

Corden, W. M. (1971): The Theory of Protection, Oxford, Reino Unioo, Clarendon Press.

Escaith, H. y C. Schatan (1996): Centroannérica: Inflación y estabilización en la crisis y poscrisis, Revista de la CEPAL, No 58 ,
LC/G.19/6-P, Santiago de Chile, Comisión Económica para Anterica Latina y el Caribe (CEPAL).

Hoffinaister, A. (1992): The cost of export subsities: Evidence from Costa Rica, Staff Papess, vol. 39, N* I, Washington, D.C., Fondo Monetario Internacional (FMI), marzo.

Lerner, A.P. (1936): The symmetry between import and expot taxes, Ecomomica, vol. 3, $\mathrm{N}^{\circ}$ 11, Londres, London School of Economy and Political Science, agosto.

SIECA (Secretaría Permanente del Tratado General de Integración Económica Centroamericana) (1974): El desarrollo integra * do de Centroamérica en la presente década, vol. 4, Buenos Aires, Babco Interamericano de Desartollo (BID)/Instituto para Ia Integración de América Latina (INTAL).

Tello, M.D. (1996): El CBT a las exportaciones de manufacturas en Nicaragua 1992-1995: un análisis de precios, quantusn y pro- 
ductos, Managua, Ministerio de Economía y Desatrolto, enero, mimer.

Webb, M. y J. Fackler (1993): Learning and the time interdependence of Costa Rican exports, Journal of Development Economics, vol. 40, $\mathrm{N}^{\circ} 2$, Amsterdam, North-Holland, abril.

Willmore, L. (1976): Trade crention, trade diversion and effective protection in the Central American Common Market, Joturnal of Development Studies, vol. 12, $\mathrm{N}^{\circ} 4$, Londres, Frank Cass, julio.
(1989): La promoción de exportaciones y la sustitución de importaciones en la industria centroamericana, Revista de la CEPAL, No 38, LC/G.1570-P, Santiago de Chile, CEPAL.

(1992): Políticas industriales en Centroamérica, Revista de la CEPAL, $N^{\circ} 48$, LC/G.1748-P, Santiago de Chile, CEPAL.

(1995): Export processing zones in the Dominican Republic, World Development, vol. 23, $\mathrm{N}^{\circ} 3$, Oxford, Pergamon Press, marzo. 